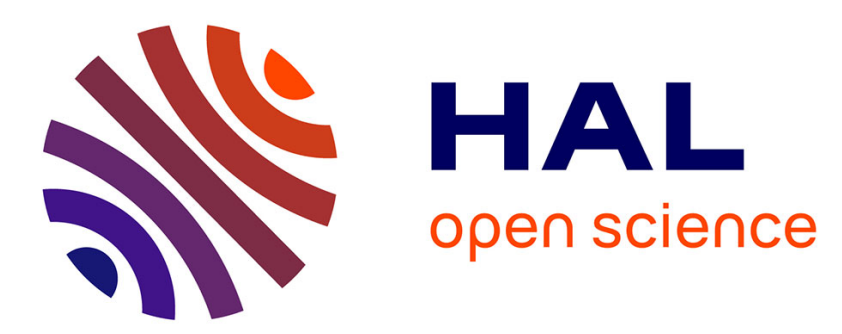

\title{
Relationship between the Gruneisen parameter, Flory-Huggins interaction parameter and other thermoacoustic parameters in dilute polymer solutions
} B. Sharma

\section{- To cite this version:}

B. Sharma. Relationship between the Gruneisen parameter, Flory-Huggins interaction parameter and other thermoacoustic parameters in dilute polymer solutions. Journal de Physique IV Proceedings, 1994, 04 (C5), pp.C5-713-C5-716. 10.1051/jp4:19945153 . jpa-00252832

HAL Id: jpa-00252832

https://hal.science/jpa-00252832

Submitted on 1 Jan 1994

HAL is a multi-disciplinary open access archive for the deposit and dissemination of scientific research documents, whether they are published or not. The documents may come from teaching and research institutions in France or abroad, or from public or private research centers.
L'archive ouverte pluridisciplinaire HAL, est destinée au dépôt et à la diffusion de documents scientifiques de niveau recherche, publiés ou non, émanant des établissements d'enseignement et de recherche français ou étrangers, des laboratoires publics ou privés. 


\title{
Relationship between the Gruneisen parameter, Flory-Huggins interaction parameter and other thermoacoustic parameters in dilute polymer solutions
}

\author{
B.K. SHARMA
}

Physics Group, DESM, National Council of Educational Research and Training, New Delhi 110016, India

\begin{abstract}
The parameter $S_{0}$ which is characteristic of melts, liquids and polymers, has also been shown to be characteristic of polymer solutions. Calculated data, using the volume expansivity of the polymer solution, establish the constancy of the $S_{0}$-parameter which retains, on an average, a constant value of 1.11 in polymer solutions. The parameter $S_{0}$ has also been shown to be related to the anharmonic Gruneisen parameter. fractional free (available) volume, solubility parameter and Flory - Huggins interaction parameter $\chi$ in dilute polymer solutions. The results have been used to develop further understanding of the significance of fractional available volume and the $S_{0}$-parameter in describing various thermo-acoustic properties and the anharmonic behaviour in polymer solutions.
\end{abstract}

\section{INTRODUCTION}

The Sharma parameter $S_{0}$ which is characteristic of molten substances at the solid-liquid phase transition, polymers and liquids at various temperatures and pressures, has. on the average, a constant value of $1.11+0.01$ in a wide variety of substances $[1-4]$. In this paper, it is shown that the $S_{0}$-parameter retains its value even in polymer solutions. There is a significant contribution of the isochoric temperature derivative of internal pressure to the thermo-acoustic and anharmonic properties of dilute polymer solutions. An attempt has also been made to relate the $S_{0}$-parameter to the anharmonic microscopic isothermal Gruneisen parameter $\Gamma^{\prime}$ (as a measure of anharmonicity of normal mode frequencylof molecular vibrations), the dimensionless Gruneisen - like parameter $\Gamma_{o}$, fractional free (available) Volume $f$ (as a measure of disorder due to increased mobility of molecules). Flory - Huggins thermodynamic interaction parameter $\chi$ (as a measure of polymer - solvent interaction) and the solubility parameter representing the square root of the cohesive energy density (as a measure of molecular cohe-sion) and evaluate them for dilute polymer solutions. Further understanding of the significance of the parameters $f, S_{0}$ and $\chi$ in describing the anharmonic behaviour with regard to molecular order and intermolecular interactions in dilute polymer solutions has been developed. 
2. THEORETICAL

The anharmonic microscopic isothermal Gruneisen parameter $\Gamma^{\prime}$, the dimensionless Gruneisen - like parameter $\Gamma_{0}$, Moelvin - Hughes parameter $C_{1}$, fractional free (available) volume $f$, isothermal volume derivative of intermolecular energy $\Phi$ and the thermodynamic Gruneisen parameter $\bar{\Gamma}$, using the expressions obtained $[1-4]$ for the anharmonic and thermo-acoustic paramters, $S_{0}$-parameter, employing only the volume expansivity $\alpha$ for a polymer solution are given as $\begin{aligned} \Gamma^{\prime} & =-(\alpha \ln \nu / d \ln V)_{T}=(1 / 2)\left[B\left(\alpha \ln \beta_{s} / d p\right)_{T}-1\right]=(2 / 3)(4+\alpha T)+\left(1-2 S_{0} / 3+4 \alpha T\right) / 2 \alpha T \\ & =(1 / 2)\left[\left(c_{1}+1\right)-2 S_{0} / \Gamma_{0} \alpha^{2} T^{2}\right]\end{aligned}$ $f=\left(V_{0} / V\right)=\left(\Gamma^{\prime}+1\right)^{-1}=\left[3+(2 \alpha T)^{-1}+(2 / 3)(1+\alpha T)-S_{0} / \alpha T(3+4 \alpha T)\right]^{-1}=(1 / 2)\left[\left(c_{1}+3\right)-2 S_{0} / \Gamma^{2} T^{2}\right]^{-1}(2)$ $S_{0}=-(x / 2)(3+4 \alpha T)=(1+2 \alpha T)(3+4 \alpha T) /(\widetilde{V})^{C_{1}}=\Gamma_{0} \alpha T(1+2 \alpha T) /(\widetilde{V})^{C_{1}}$

$(d \ln \Phi / d \ln V)_{T}=\bar{\Gamma} x=-2 S_{0} \bar{\Gamma} /(3+4 \alpha T)=-2 S_{0} \bar{\Gamma} / \Gamma_{0} \alpha T$

$\Gamma_{0}=(\alpha \vee B / R)=\tilde{V}^{1 / 3} /\left(\tilde{V}^{1 / 3} 1\right)=(3+4 \alpha T) / \alpha T=-2 S_{0} / X \alpha T=3\left(C_{1}-2\right) /(1+\alpha T)$

$c_{1}=(\alpha B / d p)_{T}=(13 / 3)+(\alpha T)^{-1}+4 \alpha T / 3=2+\Gamma_{0}(1+\alpha T) / 3$

$x=\left(d \ln P_{i} / \alpha \ln T\right)_{V}=-2(1+2 \alpha T) /(\tilde{V})^{c_{1}}$

$\tilde{V}=\left(V / V^{*}\right)=[(3+4 \alpha T) / 3(1+\alpha T)]^{3}$

$\alpha=\phi_{1} \alpha_{1}+\phi_{2} \alpha_{2}$

where $\alpha_{1}, \alpha_{2}$ represent respectively the volume expansivities of the liquid(solvent) and polymer and $\phi_{1}, \phi_{2}$ are their respective mole fractions, $R$ is the universal gas constant, $\widetilde{V}$ is the reduced specific volume, $P i$ the internal pressure, Va the available volume of the molecules, $v^{*}$ the hard core specific volume, and $v, \alpha, B$ and $B s$ are respectively the specific volume, the volume expansivity, isothermal and adiabatic bulk modulus of the polymer solution at absolute

temperature $T$ and pressure $p \cdot(6)-(9)$, the parameters $X, \Gamma^{\prime}, f$ and So have been evaluated for several equimolar polymer - solvent systems $\left(\phi_{1}=\phi_{2}=0.5\right)$ at $298 \mathrm{~K}$. The necessary experimental data on $\alpha_{1}$ and $\alpha_{2}$ to evaluate $\alpha$ are taken from literature $[3-6]$. The results are presented in Table 1.

Table 1:Calculated values of $S_{0}$ and other anharmonic parameters of polymer - solvent systems at $298 \mathrm{~K}$

\begin{tabular}{lccccc}
\hline \multicolumn{1}{c}{ System } & $\begin{array}{c}\alpha \\
\left(10^{-3} \mathrm{~K}^{-1}\right)\end{array}$ & $X$ & $\Gamma^{\prime}$ & $f$ & $S_{0}$ \\
\hline Polymethylene + polyisobutylene & 0.623 & -0.599 & 3.87 & 0.20 & 1.12 \\
Natural rubber + benzene & 0.938 & -0.544 & 3.67 & 0.21 & 1.12 \\
Polystyrene + toluene & 0.825 & -0.563 & 3.72 & 0.21 & 1.12 \\
Polystyrene + methyl ethyl Ketore 0.940 & -0.543 & 3.67 & 0.21 & 1.12 \\
Polystyrene + ethyl benzene & 0.795 & -0.568 & 3.74 & 0.21 & 1.12 \\
Polyisobutylene + n - pentane & 1.082 & -0.520 & 3.62 & 0.22 & 1.12 \\
Polyisobutylene + n - hexane & 0.970 & -0.538 & 3.66 & 0.21 & 1.12 \\
Polyisobutylene+n - heptane & 0.904 & -0.549 & 3.68 & 0.21 & 1.12 \\
Polyisobutylene + n - Octane & 0.857 & -0.557 & 3.70 & 0.21 & 1.12 \\
Polyisobutylene + n - decane & 0.802 & -0.567 & 3.73 & 0.21 & 1.12 \\
Polyisobutylene + n - hexadecane & 0.728 & -0.580 & 3.78 & 0.21 & 1.12 \\
Polyisobutylene + benzene & 0.889 & -0.552 & 3.69 & 0.21 & 1.12 \\
Polyisobutylene + cyclohexane & 0.886 & -0.552 & 3.69 & 0.21 & 1.12
\end{tabular}


The Flory - Huggins thermodynamic polymer - solvent interaction parameter $\chi$, using the expression obtained [7] for $\chi$, may be related to the $S_{0}$ - parameter, using eq. (3). for a dilute polymer solution as
$\chi=\left(1 / z^{\prime}\right)+\left(V_{1} / R T\right)\left(\delta_{2}-\delta_{1}\right)^{2}=(1 / z \xi)-\left(2 S_{0} / X_{1} \alpha_{1} T\right)\left(\delta_{2}-\delta_{1}\right)^{2} / \delta_{1}^{2}$ in which the solubility parameter $\delta_{1}$ of a liquid can be written as[8] $\delta_{1}^{2}=\left(R T / V_{1}\right)\left[\tilde{V}_{1}^{1 / 3} /\left(\tilde{V}_{1}^{1 / 3}-1\right)\right]=\left(R T / V_{1}\right)\left[\left(3+4 \alpha_{1} T\right) / \alpha_{1} T\right]=R T\left(\Gamma_{0}\right)_{1} / V_{1}$

where $\alpha_{1}$ is the volume expansivity and $\left(\Gamma_{0}\right)_{1}$ the dimensionless Gruneisen - like parameter for the liquid (solvent), $z^{\prime}=z \&$ the effective corraination number, $z$ the coordination number taken equal to 4 in dilute polymer solutions, $\&$ represents the ratio $\left(V_{1}\left\langle/ V_{2}\right\rangle\right)$ or $\left(V_{2}\left\langle/ V_{1}\right\rangle\right)$ such that $\& \leqslant 1, v_{1}, \delta_{1}$ and $v_{2}, \delta_{2}$. are respectively the molar volume and solubility parameter of the solvent and the polymer segment in dilute polymer solutions.

Using eq. (10) and taking $z=4$ the parameters $z^{\prime}, \xi$ and $\chi$ have been evaluated for several polymer - solvent system at $298 \mathrm{~K}$. The necessary experimental data on $v_{1}, v_{2}\left(\right.$ in $\left.\mathrm{Cm}^{3} / \mathrm{mol}\right)$ and $\delta_{1}, \delta_{2}\left[\mathrm{~m}\left(\mathrm{cal} / \mathrm{cm}^{3}\right)^{1 / 2}\right]$ are taken from literature $[6,9,10]$. 2 The results are presented in Table 2.

Table 2:Calculated Values of Flory-Huggins thermodynamic interaction parameter $\chi$ of polymer - solvent systems at $298 \mathrm{~K}$

\begin{tabular}{|c|c|c|c|c|c|c|c|}
\hline System & $V_{1}$ & $V_{2}$ & $\delta_{1}$ & $\delta_{2}$ & s & $z^{\prime}$ & $x$ \\
\hline olystyrene + & 106.8 & 97.75 & 8.90 & 9.10 & 0.92 & 3.66 & 0.28 \\
\hline Irofuran + & 89.4 & 70.68 & 9.20 & .55 & .79 & 3.16 & .38 \\
\hline $\begin{array}{r}\text { polytetrahydı } \\
\text { tol }\end{array}$ & 06.8 & 70 & .90 & 55 & .66 & 2.64 & 0.4 \\
\hline $\begin{array}{l}\text { olychloroprene + Car- } \\
\text { bon tetrachloride }\end{array}$ & 97.1 & 71 & 3.60 & .50 & 0.74 & 2.96 & 0.34 \\
\hline $\begin{array}{l}\text { Polyisobutylene }+n- \\
\text { pentane }\end{array}$ & 116.2 & 61 & 7.00 & .05 & 0.53 & 2.11 & 0.69 \\
\hline Natural rubber + benzene & 89.4 & 74.58 & 9.20 & 8.10 & 0.83 & 3.34 & 0.48 \\
\hline $\begin{array}{c}\text { Natural rubber +cyclo- } \\
\text { hexane }\end{array}$ & 108.7 & 74. & 8.20 & 8.10 & 0.67 & 2.74 & 0.37 \\
\hline Butyl rubber + toluene & 106.8 & 61.0 & 8.90 & 8.05 & .57 & 2.28 & 0.57 \\
\hline GR-S + chlorobenzene & 102.1 & 107.0 & 9.50 & 8.93 & 0.95 & 3.82 & 0.32 \\
\hline R-S + cyclohexane & 108.7 & 107.0 & 8.20 & 8.93 & 0.98 & 3.94 & 0.35 \\
\hline
\end{tabular}

\section{RESULTS AND DISCUSSION}

Calculated values of the quantity $X$ for several polymer - solvent systems in table 1 are negative. However, the absolute values of $X$ range from about 0.52 to 0.60 which are of the same order, as observed for melts, polymers and liquids $[1-4]$. It may be interesting to note that although the values of $\alpha$ and $x$ depend on the nature of the polymer - solvent system, the parameters So and $f$ have, on the average, constant values of $1.11+0.01,0.21+0.01$ respectively for these systems. Table 2 shows that the calculated values of the molar volumes ratios range from about 0.53 to 0.98 and those of effective cooraination number $z^{\prime}$ from about 2.11 to 3.94 
in several polymer - solvent systems at $298 \mathrm{~K}$, in close agreenent with the range from about 2 to 4 as proposed by other workers $[11,12]$. The calculated values of the interaction parameter $\chi$ are of the same order as observed earlier [9]. in good agreement with experimental values. For Natural rubber + cyclohexane system, the value of $\chi$ is 0.37 as the contribution of molar volumes ratio 3 is significant while that of $\left(\delta_{2}-\delta_{1}\right)^{2}$ is nearly zero. However, in case of polyisobutylene $+n$ - pentane system, both the factors $\&$ and $\left(\delta_{2}-\delta_{1}\right)^{2}$ contribute significantly to the value of 0.69 for $X$ inthis system.

The treatment offers a further evidence to support the constancy of the $S_{0}$ - parameter and for investigating several thermo-acoustic and anharmonic properties by relating it to the solubility parameter, the Gruneisen parameter, fractional available volume and the Flory-" Huggins interaction parameter in dilute polymer solutions.

4. REFERENCES

[1] Sharma B.K., J. Pure Appl. Ultrason. 10 (1988) $13-17$.

[2] Sharma B.K.. Phys. Stat. Sol. (a) 130 (1992) 335 - 342.

[3] Sharma B.K.., Acustica 77 (1992) $74-85$.

[4] Sharma B.K., and Reddy R.R.. Pramana - J. Phys. 28 (1987) $195-203$.

[5] Flory P.J.., Ellenson J.I. and Eichinger B.E., Macromolecules 1 (1968) $279-288$.

[6] Eichinger B.E., and Flory P.J., Trans. Faraday Soc. 64 (1968) 2035 - 2072 .

[7] Sharma, B.K., and Bhatnagar H.L., Indian J. Chem. 10 (1972) $1039-1040$.

[8] Sharma B.K.. Pramana - J. Phys. 37 (1991) 489 - 496.

[9] Huglin M.B. and Pass D.J.,J. Appl. Polym. Sci. 12 (1968) $473-485$.

[10] Barton A.F.M.. Chem Rev. 75 (1975) 731 - 753.

[11] Noel R., Patterson D. and Somcynsky T.. J. Polym. Sci. 42 (1960) 561 - 572 .

[12] Bataille P. and Patterson D.. J. Appl. Polym. Sc1. A1 (1963) $3265-3275$. 